\title{
ОЦЕНКА ТРАБЕКУЛЯРНОГО КОСТНОГО ИНДЕКСА У ПАЦИЕНТОВ С САХАРНЫМ ДИАБЕТОМ 1 ТИПА
}

\author{
'Дыдышко Ю.В., 'Шепелькевич А.П., ${ }^{2}$ Соседкова А.В., ${ }^{3}$ Васильева Н.А., ${ }^{4}$ Водянова О.В. \\ 'УО «Белорусский государственный медицинский университет» \\ гуз «МГКОД»

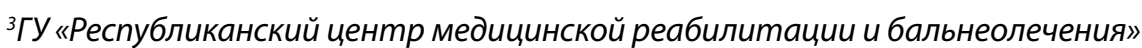

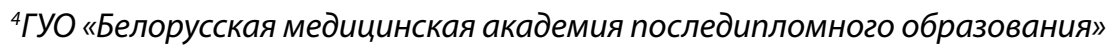

ЦЕЛЬ: Медико-социальная значимость проблемы сахарного диабета (СД) определяется увеличением числа пациентов и развитием хронических осложнений. Наличие диабетической остеопатии не вызывает сомнений, но понимание механизмов ее формирования и диагностики требуются дополнительные сведения. Таким образом, целью работы был анализ состояния как количественных (минеральная плотность кости, МПК), так и качественных параметров кости (трабекулярный костный индекс, ТКИ).

МАТЕРИАЛЫ И МЕТОДЫ: Проведено одномоментное поперечное исследование 157 пациентов с СД 1-го типа и 98 практически здоровых лиц, составивших контрольную группу, на базе ГУ «Республиканский центр медицинской реабилитации и бальнеолечения». Комплексное клиническое обследование включало оценку антропометрических данных (рост, вес, индекс массы тела, окружность талии), биохимический анализ крови, ДРА осевого скелета на денситометре «PRODIGY LUNAR» фирмы General Electric Medical Systems (США), 2004 года выпуска. При интерпретации Z-критерия МПК у лиц молодого возраста снижение данного параметра от $-2,0$ и менее расценивалось как низкая минеральная плотность кости

РЕЗУЛЬТАТЫ И ИХ ОБСУЖДЕНИЕ: СРеДниЙ возраст пациентов С СД 1-го типа и лиц контрольной группы составил 32,3 (25,5-41,6) и 30,5 $(24,7-36,0)$ лет соответственно, средняя длительность заболевания - 13 лет (от 2 до 35 лет), возраст манифестации диабета - 17 лет. Средний уровень НbA1с у пациентов с СД 1-го типа составил 8,2 (7,6-8,9)\%.

Низкая костная масса выявлена у 14,6\% (23 человека) пациентов с СД 1-го типа и у 4,1\% (4 человека) лиц контрольной группы ( $F=0,03 ; p=0,007)$. Установлены достоверно более низкие значения ТКИ поясничного отдела позвоночника у пациентов с СД 1-го типа по сравнению с контролем $(1,40(1,33-1,46)$ vs 1,44 $(1,39-1,48)$; U=2775; $\mathrm{p}<0,001)$ с наибольшим снижением ТКИ в первом поясничном позвонке $(1,29(1,22-1,39)$ vs $1,34(1,29-1,42)$; $\mathrm{U}=2898 ; \mathrm{p}=0,002)$. Методом рангового дисперсионного анализа по Фридмену подтверждены различия распределения ТКИ с наибольшим снижением в области первого поясничного позвонка ( $\left.\mathrm{rr}^{2}=165,12 ; \mathrm{p}<0,001\right)$.

У мужчин и женщин группы контроля не выявлены достоверные различия значений ТКИ поясничного отдела позвоночника $(1,46(1,43-1,53)$ vs $1,43(1,39-1,47) ; U=373 ; p=0,166)$. Аналогичные результаты получены у пациентов с СД 1-го типа: $(1,42(1,37-1,47)$ vs $1,39(1,33-1,44) ; U=1385 ; p=0,257)$ у мужчин и женщин соответственно. Отсутствовали достоверные различия значений ТКИ поясничного отдела позвоночника в подгруппах с нормальными и сниженными значениями МПК у пациентов с СД 1-го типа $(1,41(1,34-1,46)$ vs $1,36(1,27-1,43) ; U=725 ; p=0,065)$. и в группе контроля $(1,45(1,39-1,48)$ vs $1,42(1,38-1,49) ; U=107 ; p=0,767)$.

Установлена прямая слабая статистически значимая связь показателей ТКИ и МПК поясничного отела позвоночника у пациентов с СД 1-го типа ( $\rho=0,29 ; p=0,001)$, что подтверждает однонаправленные изменения данных параметров. Аналогично подтверждена прямая слабая достоверная связь показателей ТКИ и МПК поясничного отела позвоночника у лиц контрольной группы $(\rho=0,29 ; p=0,001)$. У пациентов с СД 1-го типа выявлена обратная слабая достоверно значимая связь значений тощаковой гликемии и ТКИ поясничного отдела позвоночника ( $\rho=-0,26 ; p=0,048)$.

ВЫВОДЫ: у пациентов с СД 1-го типа установлены более низкие значения ТКИ поясничного отдела позвоночника с наибольшим снижением ТКИ в первом поясничном позвонке. У мужчин и женщин выявлены сопоставимые значения ТКИ. Установлена прямая слабая статистически значимая связь показателей ТКИ и МПК поясничного отела позвоночника у пациентов с СД 1-го типа, однако отсутствовали достоверные различия значений ТКИ в подгруппах с нормальной и сниженной МПК.

КЛЮЧЕВЫЕ СЛОВА: трабекулярный костный индекс, минеральная плотность кости, сахарный диабет 1-го типа. 